\title{
Coordination of consolidated bioprocessing technology and carbon dioxide fixation to produce malic acid directly from plant biomass in Myceliophthora thermophila
}

Jingen $\mathrm{Li}^{1,2+}$, Bingchen Chen ${ }^{1,2,3 \dagger}$, Shuying Gu ${ }^{1,2,3 \dagger}$, Zhen Zhao ${ }^{1,2,3}$, Qian Liu ${ }^{1,2}$, Tao Sun ${ }^{1,2}$, Yongli Zhang ${ }^{1,2}$, Taju Wu $\mathbf{W u}^{1,2}$, Defei Liu ${ }^{1,2}$, Wenliang Sun ${ }^{1,2}$ and Chaoguang Tian ${ }^{1,2^{*}}$

\begin{abstract}
Background: Consolidated bioprocessing (CBP) technique is a promising strategy for biorefinery construction, producing bulk chemicals directly from plant biomass without extra hydrolysis steps. Fixing and channeling $\mathrm{CO}_{2}$ into carbon metabolism for increased carbon efficiency in producing value-added compounds is another strategy for cost-effective bio-manufacturing. It has not been reported whether these two strategies can be combined in one microbial platform.

Results: In this study, using the cellulolytic thermophilic fungus Myceliophthora thermophila, we designed and constructed a novel biorefinery system DMCC (Direct microbial conversion of biomass with $\underline{\mathrm{CO}_{2}}$ fixation) through incorporating two $\mathrm{CO}_{2}$ fixation modules, PYC module and Calvin-Benson-Bassham (CBB) pathway. Harboring the both modules, the average rate of fixing and channeling ${ }^{13} \mathrm{CO}_{2}$ into malic acid in strain CP51 achieved 44.4, 90.7, and $80.7 \mathrm{mg} / \mathrm{L} / \mathrm{h}$, on xylose, glucose, and cellulose, respectively. The corresponding titers of malic acid were up to $42.1,70.4$, and $70.1 \mathrm{~g} / \mathrm{L}$, respectively, representing the increases of $40 \%, 10 \%$, and $7 \%$, respectively, compared to the parental strain possessing only PYC module. The DMCC system was further improved by enhancing the pentose uptake ability. Using raw plant biomass as the feedstock, yield of malic acid produced by the DMCC system was up to $0.53 \mathrm{~g} / \mathrm{g}$, with ${ }^{13} \mathrm{C}$ content of $0.44 \mathrm{~mol} / \mathrm{mol}$ malic acid, suggesting DMCC system can produce $1 \mathrm{t}$ of malic acid from $1.89 \mathrm{t}$ of biomass and fix $0.14 \mathrm{t} \mathrm{CO}_{2}$ accordingly.

Conclusions: This study designed and constructed a novel biorefinery system named DMCC, which can convert raw plant biomass and $\mathrm{CO}_{2}$ into organic acid efficiently, presenting a promising strategy for cost-effective production of value-added compounds in biorefinery. The DMCC system is one of great options for realization of carbon neutral economy.
\end{abstract}

Keywords: Myceliophthora, Metabolic engineering, $\mathrm{CBB}$ cycle, $\mathrm{CO}_{2}$-fixation, Plant biomass, Malic acid

*Correspondence: tian_cg@tib.cas.cn

†Jingen Li, Bingchen Chen and Shuying Gu contributed equally to this work

${ }^{1}$ Key Laboratory of Systems Microbial Biotechnology, Tianjin Institute of Industrial Biotechnology, Chinese Academy of Sciences, Tianjin 300308, China

Full list of author information is available at the end of the article

\section{Background}

Concern over global climate charge and unstable petroleum supply has led to a greater emphasis on renewable energy sources to decrease reliance on fossil fuels [1, 2]. As a non-edible plant material, lignocellulosic biomass has long been recognized as a potential sustainable 
source for many industrial applications and green biosynthesis of biofuels and commodity chemicals. However, because of the recalcitrant nature of lignocellulose to enzymatic hydrolysis, the costs of conversion of insoluble lignocellulosic materials to fermentable sugars represent a significant barrier to the production of cost-competitive biofuels [3, 4]. Consolidated bioprocessing (CBP), featuring the hydrolysis and fermentation in a single process step without adding any extra cellulases, is widely recognized as a promising strategy for cost-effective production of plant biomass-derived biofuels and chemicals [5]. CBP entails microbial engineering by functional expression of cellulases in a fermentative organism, or incorporation of the desired product-synthesis pathway into a cellulase-producing organism $[3,6]$. Recently, cellulolytic organisms, such as Trichoderma [7], Aspergillus, Clostridium [8], and Myceliophthora [9, 10] have been tried as CBP strains for direct conversion of plant cell wall materials into biofuels and biochemicals, including ethanol [11], isobutanol [12], itaconic acid [13], and malic acid $[9,10]$.

$\mathrm{CO}_{2}$ is also a potentially scalable raw material to produce sustainable fuels and chemicals that could be alternatives to petroleum products. Fixing and channeling $\mathrm{CO}_{2}$ into the central carbon metabolism of industrial microbes has potential to reduce the $\mathrm{CO}_{2}$ level in the environment and increase carbon efficiency in the production of value-add compounds, for example, production of succinic or acetic acid from methanol and $\mathrm{CO}_{2}$ [14]. Several $\mathrm{CO}_{2}$ fixation pathways, including the Calvin-Benson-Bassham (CBB) cycle, the 3-hydroxypropionate bicycle, and methanol condensation pathways, have been introduced into heterotrophic organisms, such as Escherichia coli, Saccharomyces cerevisiae, Pichia pastoris, and Methylobacterium extorquens [15-22].

The $\mathrm{CBB}$ cycle, also known as the reductive pentose phosphate cycle, is the most dominant $\mathrm{CO}_{2}$ fixation pathway of the seven known natural alternatives [23-25]. The CBB cycle employs 11 enzymes to complete autotrophic $\mathrm{CO}_{2}$ fixation. Most of these enzymes are also involved in central metabolism, including glycolysis and the pentose phosphate pathway [26]. Ribulose-1,5-bisphosphate carboxylase-oxygenase (RuBisCO) and phosphoribulokinase (PRK) are the two key enzymes of the CBB cycle. PRK catalyzes phosphorylation of ribulose-5-phosphate, a normal intermediate of pentose phosphate pathway, to ribulose-1,5-biphosphate. RuBisCO is the one enzyme that is specific to the CBB cycle, and catalyzes the carboxylation of ribulose-1,5-bisphosphate with $\mathrm{CO}_{2}$ to generate two molecules of 3-phosphoglycerate [27]. Functional overexpression of genes encoding $\mathrm{RuBisCO}$ and $\mathrm{PRK}$ in E. coli resulted in significantly decreased release of $\mathrm{CO}_{2}$ $[20,22,28]$ and the biosynthesis of sugar from $\mathrm{CO}_{2}[29]$.
Based on construction of RuBisCO-dependent E. coli, a RuBisCO mutant with higher activity and better solubility was selected [30,31]. Recycling $\mathrm{CO}_{2}$ into the central metabolic network is a promising approach for expanding the use of $\mathrm{CO}_{2}$ fixation to improve the yield of target metabolites. In S. cerevisiae, parts of the CBB cycle have been integrated into the metabolic network to enable the use of $\mathrm{CO}_{2}$ as an additional electron acceptor for the reoxidation of $\mathrm{NADH}$ and simultaneous recycling of $\mathrm{CO}_{2}$ released from the decarboxylation of pyruvate, resulting in increased productivity and yield of ethanol [17, 21, 32]. Recently, a non-native CBB cycle has been introduced into heterotrophic organisms to generate autotrophic or mixotrophic organisms, coupling of modification of central metabolic pathway. Antonosky et al. engineered $E$. coli to hemi-autotrophically grow on $\mathrm{CO}_{2}$, with reducing power and energy from oxidation of pyruvate [29]. In follow-up studies, $E$. coli and P. pastoris were converted into autotrophs, which could incorporate $\mathrm{CO}_{2}$ into biomass, respectively, using formate or methanol as the energy source for a heterologous CBB cycle $[18,33]$. Pentoses, including xylose and arabinose, are metabolized by pentose phosphate pathway, where the intermediate ribulose-5-phosphate can serve as the substrate of PRK. Previously, xylose and arabinose were used as the feedstock to drive $\mathrm{CO}_{2}$-fixation by the $\mathrm{CBB}$ cycle in $E$. coli and $S$. cerevisiae $[17,20,32]$.

Malic acid is widely used in the food industry as the acidulant and flavor enhancer and it was selected as one of the 12 most important building block chemicals available from renewable biomass by the US Department of Energy in 2004. Studies evaluating microbial malate production have attracted much industrial attention. Four native metabolic pathways that produce malic acid from glucose have been identified and analyzed [34]. The reductive tricarboxylic acid (rTCA) pathway, with theoretical yield of $2 \mathrm{~mol} \mathrm{malic} \mathrm{acid} / \mathrm{mol}$ glucose, is considered the most efficient pathway, because of the $\mathrm{CO}_{2}$ fixation during the carboxylation reaction of pyruvate to oxaloacetate catalyzed by pyruvate carboxylase [34]. Filamentous fungi offer great potential advantages in the use of complex carbon sources and production of organic acids at high concentration with yield near the theoretical maximum, and several such species have been engineered as cell factories for producing malic acid, including Aspergillus, Penicillium, Rhizopus, and Myceliophthora [35-38].

The thermophilic filamentous fungus Myceliophthora thermophila (synonym Thermothelomyces thermophilus), which is able to secrete a large amount of hydrolytic enzymes and grow robustly on cellulosic materials, is exceptionally attractive for biorefinery construction $[39,40]$. A suite of molecular biology tools, including 
CRISPR/Cas9 method, are available for M. thermophila, which allow rational genetic engineering. Previously, we enhanced the synthetic pathway and export system of malic acid in M. thermophila and the resultant transformant was able to produce malic acid by direct conversion of hemicellulose or cellulose without adding extra hydrolase [9]. The major components of plant cells are made from hexose (glucose) and pentoses (xylose and arabinose). Pentose is catabolized via the pentose phosphate pathway and can actuate $\mathrm{CO}_{2}$-fixation during the $\mathrm{CBB}$ cycle.

In this study, the $\mathrm{CBB}$ cycle enzymes RuBisCO and PRK were introduced into the cellulolytic fungus $M$. thermophila to form a novel biorefinery system-called DMCC (Direct microbial conversion of biomass with $\mathrm{CO}_{2}$ fixation) here-to produce a bulk chemical (malic acid) from plant biomass and $\mathrm{CO}_{2}$ (Fig. 1). The function of the heterologous $\mathrm{CBB}$ cycle was demonstrated by growth phenotype, ${ }^{13} \mathrm{C}$-tracer analysis, and increased production of malic acid. Moreover, branches from the malate synthesis pathway were deleted by gene knockin technology mediated through the CRISPR/Cas9 system, and genetic manipulation for improved uptake of pentose was performed. The combined effects of these manipulations led to improved malic acid titer and yield directly from plant biomass (corncob) and $\mathrm{CO}_{2}$, exhibiting the latest progress in CBP strategy.

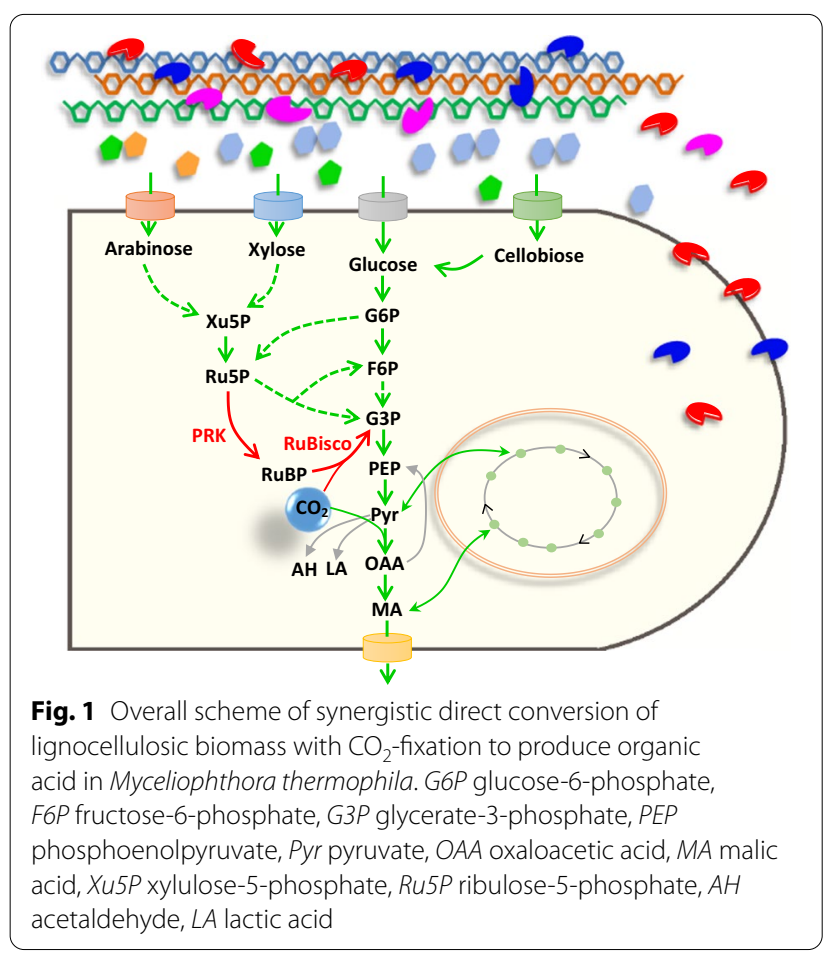

\section{Results}

Heterologous expression of genes encoding CBB cycle enzymes in $M$. thermophila

Previously, we performed metabolic modification in $M$. thermophila to generate strain JG207, which can produce malic acid using plant lignocellulose as the carbon source [9]. Efficient utilization of the main components of lignocellulose (glucose, xylose, and arabinose) is a prerequisite for improvement in three major indices of performance (titer, yield and productivity) in the biological production of plant cell-derived biochemicals. In microbial cells, xylose and arabinose are metabolized by pentose phosphate pathway, which can provide the substrate (ribulose-5-phosphate) for PRK of the CBB cycle. The genes encoding CBB cycle enzymesRuBisCO and PRK-have been introduced into heterotrophic microbes to recycle $\mathrm{CO}_{2}$ and driven by pentose to improve production of target metabolites [17, 29, 32]. It was reported that prokaryotic form-II RuBisCOs are encoded by a single structural gene [27]. The RuBisCO gene from $R$. rubrum ( $c b b M$ ) has been functionally overexpressed in M. extorquens, E. coli and $S$. cerevisiae $[17,19]$. Therefore, to improve malate production by $M$. thermophila, $c b b M$ was integrated into the genome of strain JG207, together with prk from $S$. oleracea, under the control of the strong constitutive promoters of $g p d A$ and $p d c$, respectively. After confirmation of the presence of the transgenes by PCR analysis, physiological characterization of the resultant strain, named as CP-1, was conducted using xylose or arabinose as the carbon source.

RT-qPCR analysis indicated that six copies of prk and eight copies of $c b b M$ were integrated into the genome of strain CP-1 (Additional file 2: Fig. S2). RuBisCO was active in strain CP-1 when $c b b M$ was overexpressed. The RuBisCO activity in the crude extract of this strain achieved $22.3 \mathrm{U} / \mathrm{mg}$ protein, while in the parent strain JG207, the activity was undetectable (Fig. 2a). As shown in Fig. 2, simultaneous overexpression of $\mathrm{RuBisCO}$ and PRK contributed to malate production from xylose or arabinose. Starting with $75 \mathrm{~g} / \mathrm{L}$ carbon source, the titer of malic acid reached $37.3 \mathrm{~g} / \mathrm{L}$ and $54.1 \mathrm{~g} / \mathrm{L}$ from xylose and arabinose, respectively, $24 \%$ and $15 \%$ increases compared with parental strain JG207 (malate titers $30 \mathrm{~g} / \mathrm{L}$ and $47 \mathrm{~g} / \mathrm{L}$ from xylose and arabinose, respectively). Moreover, increases in cell dry weight of strain CP-1 on xylose (1.38-fold) and arabinose (1.18-fold) were confirmed, compared with strain JG207. These results indicated that integration of the CBB cycle enzymes into the carbon metabolic pathway of a filamentous fungus was beneficial for malate production and cell growth when using pentoses as the feedstock. 
a

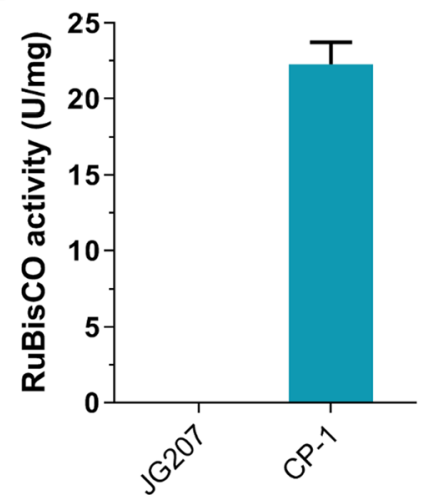

b

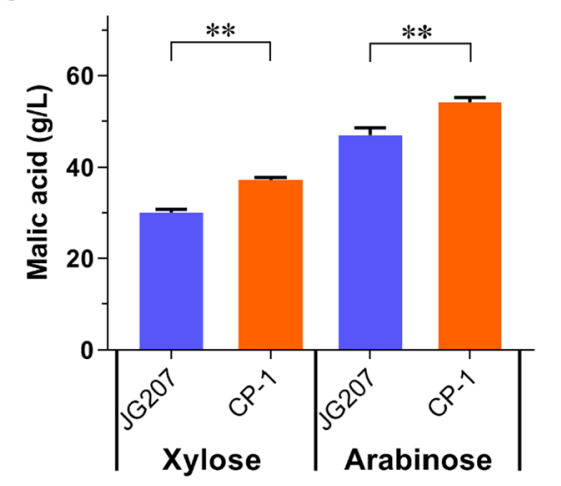

C

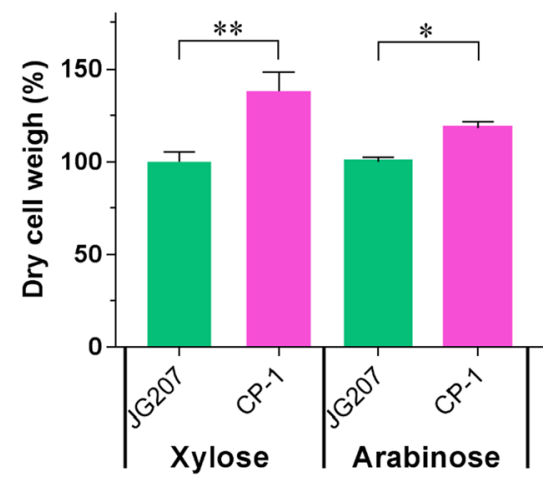

Fig. 2 Physiological characterization of $M$. thermophila strain CP-1 overexpressing genes encoding ribulose-1,5-bisphosphate carboxylase/ oxygenase (RuBisCO) and phosphoribulokinase (PRK). a RuBisCO activity in M. thermophila CP-1. b Titers of malic acid in culture of strain CP-1 when grown on xylose or arabinose after 8 days in shaking flasks. $\mathbf{c}$ Dry cell weight of culture of strain CP-1 grown on xylose or arabinose for 4 days. The values and error bars represent means and standard deviations

\section{Simultaneous $\mathrm{CO}_{2}$-fixation and branch pathway disruption were propitious to the production of malic acid}

Based on the observations described above, we found that the engineered strain containing CBB cycle enzymes had an advantage in malate production. We then applied another metabolic engineering strategy: disruption of the branch points of the synthetic pathway of the target chemical (malic acid) while overexpressing the CBB cycle enzymes. Previous study indicated that in microbes, pyruvate decarboxylase and lactate dehydrogenase, encoded by $p d c$ and $l d h$, respectively, use pyruvate as a substrate. These reactions limit organic acid production via the rTCA pathway $[9,41]$. Moreover, phosphoenolpyruvate (PEP) carboxykinase (PCK) functions on inverse reaction of PEP to oxaloacetate, the precursor for malate synthesis, in M. thermophila, and has been considered as a target of metabolic engineering to improve production of malic acid [9]. In M. thermophila, the genes $p d c, l d h$, and $p c k$ show high expression levels in response to various carbon sources $[40,42]$. Therefore, here, $p r k, c b b M$, and the selective marker gene neo were integrated into the $l d h, p d c$, and $p c k$ loci, respectively, in the genome of strain JG207, using the CRISPR/Cas9 system. Thus, the CBB cycle enzymes would be heterologously expressed and branch pathways were simultaneously deleted, forming strain CP-51.

When grown on xylose, strain CP-51 displayed 1.40fold and 1.13-fold increases in malate production compared with the values for strains JG207 and CP-1, respectively. The titer of malic acid was up to $42.1 \mathrm{~g} / \mathrm{L}$ (Fig. 3b). The dry cell weight of strain CP-51 showed a $59 \%$ increase compared with that of the parental strain JG207 (Additional file 2: Fig. S3). Consistently, strain CP-51 was superior to strains JG207 and CP-1 in production of malic acid using arabinose, glucose, and even cellulose (Avicel) as the carbon source. Titers of malic acid produced by strain CP-51 grown on arabinose, glucose and Avicel in flask culture were improved to $58.0 \mathrm{~g} / \mathrm{L}, 70.4 \mathrm{~g} / \mathrm{L}$, and $70.1 \mathrm{~g} / \mathrm{L}$, respectively. The corresponding yields were $0.77 \mathrm{~g} / \mathrm{g}, 0.94 \mathrm{~g} / \mathrm{g}$ and $0.93 \mathrm{~g} / \mathrm{g}$ carbon source, respectively. In addition, due to the disruption of $p c k$ and $l d h$, ethanol and lactate were undetectable in the culture. These results revealed that the combination of integration of $\mathrm{CBB}$ cycle enzymes and disruption of branch pathways contributed to further improvement of malate production from lignocellulosederived sugars.

\section{Confirmation of $\mathrm{CO}_{2}$-fixation by ${ }^{13} \mathrm{C}$-tracer analysis}

To confirm $\mathrm{CO}_{2}$ fixation during production of malic acid, ${ }^{13} \mathrm{C}$-tracer analysis was performed to detect the relative abundances of malic acid with ${ }^{13} \mathrm{C}$ atom after fermentation was over. In malic acid-producing strain JG207, malic acid can be synthesized via rTCA pathway, where pyruvate is catalyzed to oxaloacetate by pyruvate carboxylase (PYC), companied by $\mathrm{CO}_{2}$ fixation. In order to estimate the efficiency of $\mathrm{CO}_{2}$ fixation by PYC module, ${ }^{13} \mathrm{C}$-tracer analysis was carried out in strain JG207 when grown on xylose, glucose or Avicel. As shown in Fig. 4, the contents of ${ }^{13} \mathrm{C}$ molecular were up to $0.34,0.65$, and $0.55 \mathrm{~mol} / \mathrm{mol} \mathrm{malic}$ acid on xylose, glucose, and Avicel, respectively, after 8 days of fermentation. The corresponding average rates of fixating and channeling ${ }^{13} \mathrm{CO}_{2}$ into malic acid achieved 17.3, 71.1, and $62.0 \mathrm{mg} / \mathrm{L} / \mathrm{h} . \mathrm{CO}_{2}$ fixation by rTCA. These data indicated that when grown on xylose, efficiency of $\mathrm{CO}_{2}$ fixation was lower than that on glucose and Avicel. Malic acid was mainly produced by rTCA pathway under glucose and Avicel conditions. 


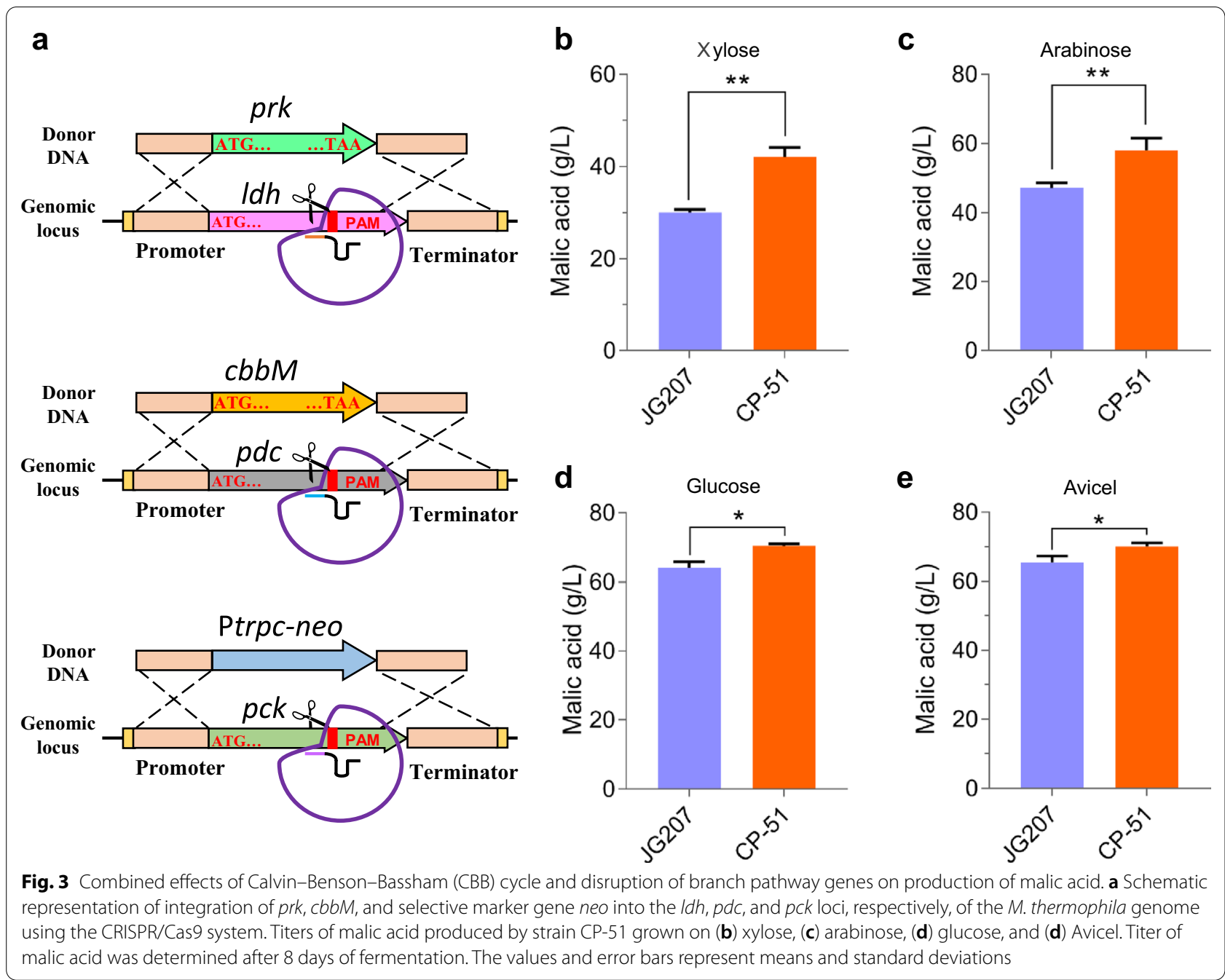

When using engineered strains $\mathrm{CP}-1$ and CP-51 to produce malic acid, we found that the average rates of fixing and channeling ${ }^{13} \mathrm{CO}_{2}$ into malic acid achieved $32.2 \mathrm{mg} / \mathrm{L} / \mathrm{h}$ and $44.4 \mathrm{mg} / \mathrm{L} / \mathrm{h}$ on xylose, representing 1.86- and 2.57-fold higher than that of strain JG207 (Fig. 4a). This enhancement led to $50 \%$ and $83 \%$ increases in contents of ${ }^{13} \mathrm{C}$ in malic acid, achieving 0.51 and $0.62 \mathrm{~mol} / \mathrm{mol}$ malic acid in strain CP-1 and CP-51, respectively (Fig. $4 \mathrm{~b}$ ). The relative abundance of malic acid with one ${ }^{13} \mathrm{C}$ atom on xylose was improved by $73.2 \%$ and $120 \%$, respectively, compared to the parental strain JG207. Meanwhile, the relative abundance of malic acid with two ${ }^{13} \mathrm{C}$ atoms produced by strains $\mathrm{CP}-1$ and $\mathrm{CP}-51$ exhibited $12.3 \%$ and $22.7 \%$ more than that by strain JG207 (Fig. 4c).

When grown on glucose and cellulose (Avicel), enhancement of $\mathrm{CO}_{2}$ fixation was also observed after integration of CBB cycle enzymes (Fig. $4 \mathrm{~d}-\mathrm{g}$ ). The average rates of fixing and channeling ${ }^{13} \mathrm{CO}_{2}$ into malic acid in strains CP-1 and CP-51 were increased by $17.2 \%$ and $27.6 \%$, respectively, and up to $83.3 \mathrm{mg} / \mathrm{L} / \mathrm{h}$ and $90.7 \mathrm{mg} / \mathrm{L} / \mathrm{h}$, respectively, compared to strain JG207 on glucose (Fig. 4e). The corresponding contents of ${ }^{13} \mathrm{C}$ in malic acid achieved 0.73 and $0.75 \mathrm{~mol} / \mathrm{mol}$ malic acid, respectively. When using cellulose (Avicel) as the feedstock, content of ${ }^{13} \mathrm{C}$ in malic acid produced by strain CP-51 was up to $0.67 \mathrm{~mol} / \mathrm{mol}$ malic acid (Fig. $4 \mathrm{~g}$ ), indicating that the production of $1 \mathrm{~mol}$ of malic acid is accompanied by the fixation of at least $0.67 \mathrm{~mol} \mathrm{CO}_{2}$. The average rate of fixing ${ }^{13} \mathrm{CO}_{2}$ for synthesizing malic acid achieved $80.7 \mathrm{mg} / \mathrm{L} / \mathrm{h}$. In addition, it was observed that ${ }^{13} \mathrm{CO}_{2}$ fixation rates of all three strain on glucose and Avicel were much higher than that on xylose. These data indicated that enhancement of $\mathrm{CO}_{2}$ fixation resulted from combined effort of pyruvate carboxylation by pyruvate carboxylase and the $\mathrm{CBB}$ cycle during malate production. It was noteworthy that the relative abundance of malic acid without ${ }^{13} \mathrm{C}$ atoms was high in the cultures 


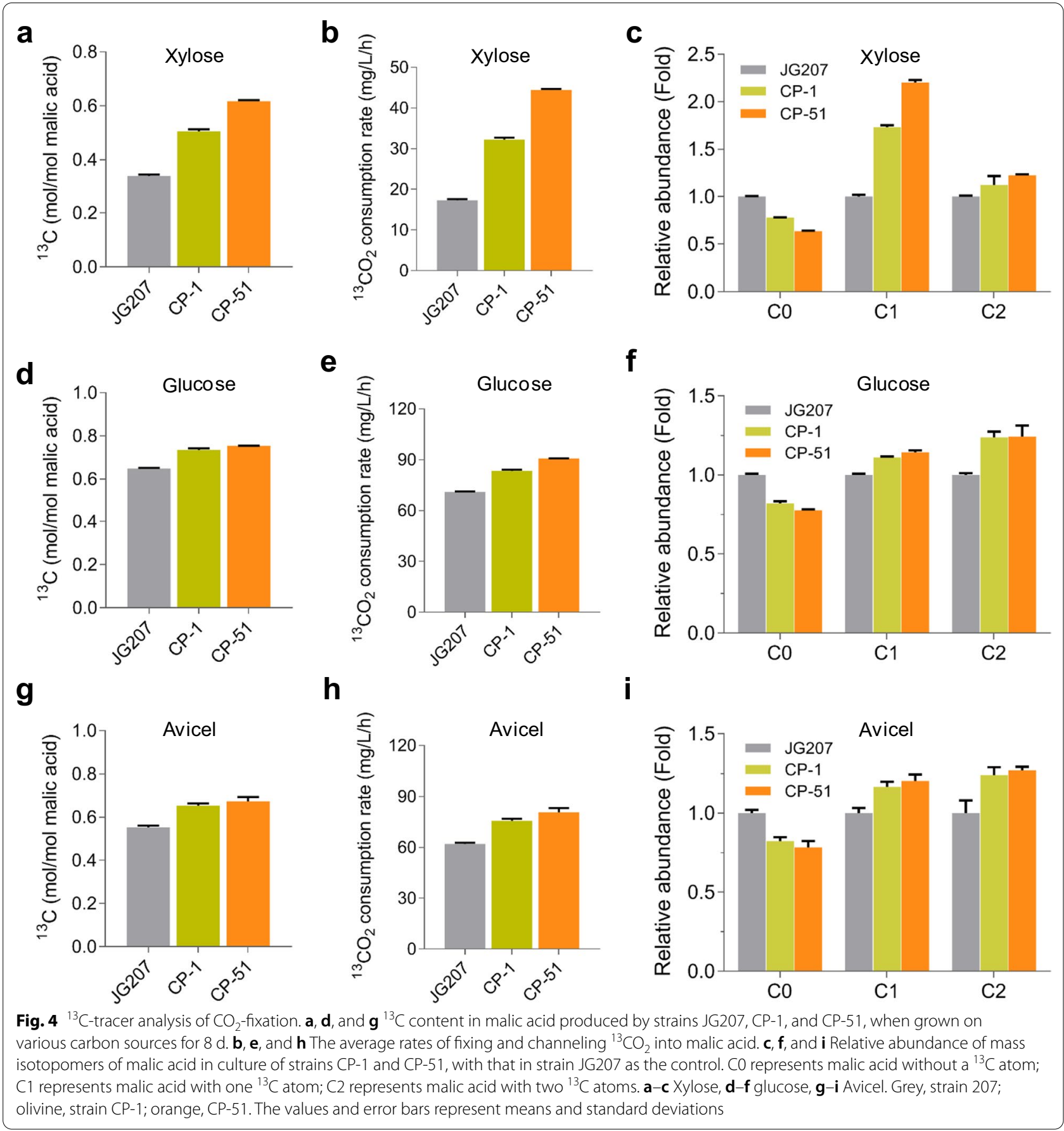

of the three strains, which might result from that more malic acid were synthesized by other pathways without $\mathrm{CO}_{2}$ fixation on xylose, such as the mitochondrial TCA cycle and the glyoxylate pathway.

Enhanced pentose uptake facilitates pentose fermentation The capability for $\mathrm{CO}_{2}$-fixation in engineered strain CP-51 is related to pentose phosphate pathway activity, which can be driven by pentose metabolism. However, xylose use is inhibited by the presence of glucose in the feedstock [43]. Enhancement of pentose uptake can alleviate this inhibition and facilitate improved pentose use and elevated co-fermentation rates of hexose and pentose [44]. Previous study showed that N376F mutation in the Gal2 protein, a galactose/glucose transporter from S. cerevisiae, led to improved affinity for xylose and 
Gal2-N376F becomes a glucose inhibition-free xylose transporter [45]. To further improve the use of pentose to provide the precursor for the $\mathrm{CBB}$ cycle, the gene encoding Gal2-N376F (Gal2M), driven by the strong constitutive promoter of eif (encoding elongation initial factor), was introduced into strain CP-51. RT-qPCR analysis indicated that eight copies of gal $2 M$ were integrated into the genome of the resultant strain Gal-1. As we expected, increases in the transport rate of xylose (1.20-fold) and arabinose (1.26-fold) by strain Gal-1 were observed, compared with strain CP-51. The glucose uptake rate was similar to that in the parental strain CP-51 (Fig. 5a-c).

To test the benefits of gal2M overexpression on the use of lignocellulosic sugar, strain Gal-1 was incubated in Vogel's minimal medium supplemented with single or multiple sugars, including glucose, xylose, and arabinose. Enhanced consumption rates of xylose and arabinose were observed in strain Gal-1 compared with strain CP-51 when they were grown with a single sugar as the carbon source. The utilization rate of glucose by strain Gal-1 was similar to that by strain CP-51. When growth in Vogel's minimal medium supplemented with the mixture of sugars, the level of sugar consumption in strain Gal-1 was considerably higher than that in strain CP-51 (Additional file 2: Fig. S5). When growth on malate-producing medium containing $40 \mathrm{~g} / \mathrm{L}$ glucose, $20 \mathrm{~g} / \mathrm{L}$ xylose, and $20 \mathrm{~g} / \mathrm{L}$ arabinose, which is similar to the components of the hydrolysate of plant biomass, the substrate consumption rate of strain Gal-1 was faster than that of the parental strain CP-51 (Fig. 5d). After 10 days of fermentation, strain Gal- 1 achieved a malate titer of $76.1 \mathrm{~g} / \mathrm{L}$, a 1.22 -fold increase compared with strain CP-51 (62.5 g/L). The corresponding yield was up to $1.01 \mathrm{~g} / \mathrm{g}$ carbon source in flask cultivation (Fig. 5e). These results indicate that improvement of pentose uptake can facilitate pentose utilization and improve cofermentation rates of hexoses and pentoses for production of malic acid.

\section{Conversion of plant biomass and $\mathrm{CO}_{2}$ into malic acid using M. thermophila}

In real-word applications, direct utilization of raw plant biomass as the feedstock is the greatest advantage of CBP technique and critical to overcome the remaining a

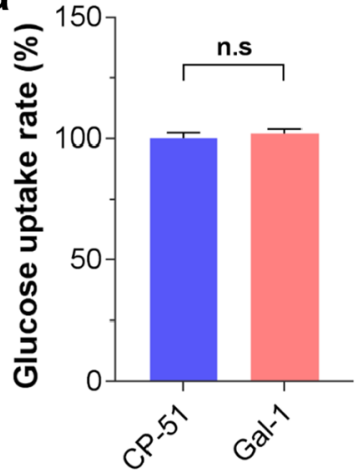

b

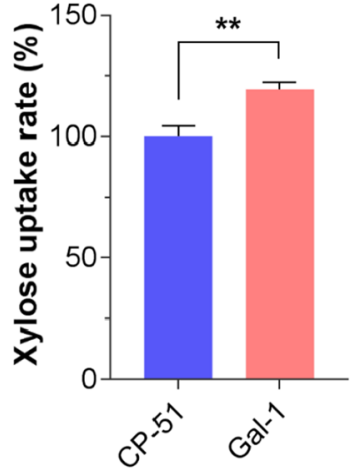

C

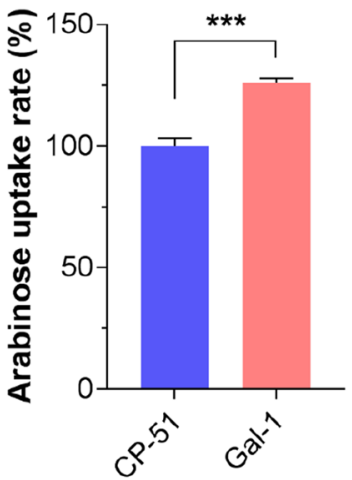

d

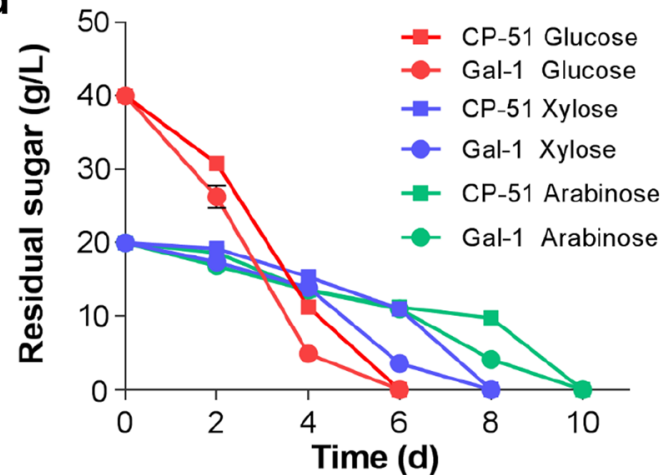

e

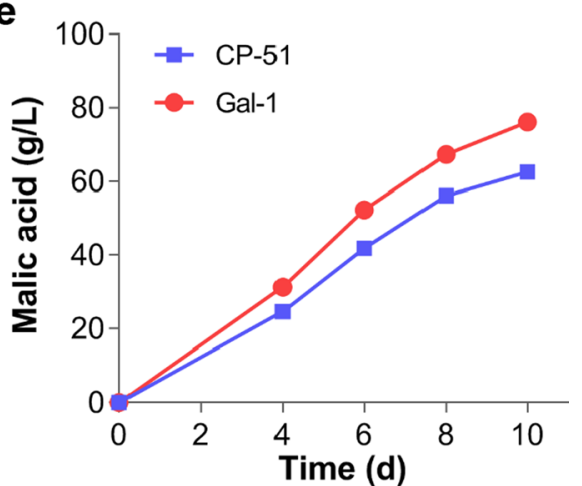

Fig. 5 Physiological characterizations of strain Gal-1 overexpressing transporter gene gla2M. Substrate transport rates of the mycelia from strain Gal-1 for $\mathbf{a}$ glucose, $\mathbf{b}$ xylose, and $\mathbf{c}$ arabinose. Time-course of sugar consumption (d) and malate production (e) by strain Gal-1 grown on malate-producing medium supplemented with a mixture of sugars (40 g/L glucose, $20 \mathrm{~g} / \mathrm{L}$ xylose, and $20 \mathrm{~g} / \mathrm{L}$ arabinose). The values and error bars represent means and standard deviations 
barriers to cost-effective production of biofuels and commodities. To test the combined effects of incorporation of the CBB cycle, disruption of branch points of the malate synthesis pathway, and enhancement of substrate uptake on production of malic acid from lignocellulosic biomass, we tested the use of pulverized raw corncob without pretreatment by alkali, acid, or hydrolytic enzymes as the feedstock for malate production. Starting with $75 \mathrm{~g} / \mathrm{L}$ raw corncob, the titer of malic acid in strain Gal-1 was up to $40 \mathrm{~g} / \mathrm{L}, 10.4 \%$ more than that in the original strain JG207 [9]. The yield of malic acid from raw corncob were up to $0.53 \mathrm{~g} / \mathrm{g}$ total plant biomass (Fig. 6a). These data represent the highest yield of malate production yet reported from raw plant biomass. ${ }^{13} \mathrm{C}$-tracer analysis indicated when grown on raw corncob, the average rate of ${ }^{13} \mathrm{CO}_{2}$ fixation for malic acid synthesis achieved $33.8 \mathrm{mg} / \mathrm{L} / \mathrm{h}$ and the content of ${ }^{13} \mathrm{C}$ atom in malic acid was up to $0.44 \mathrm{~mol} / \mathrm{mol}$ malic acid (Fig. 6b), suggesting that $1 \mathrm{t}$ of malic acid could be produced from $1.89 \mathrm{t}$ of biomass with $0.14 \mathrm{t}$ of $\mathrm{CO}_{2}$ fixation. Our results clearly show the synergy between lignocellulosic biomass conversion and $\mathrm{CO}_{2}$-fixation for producing organic acids.

As expected, the titer and yield of malic acid on corncob shown less than that on crystalline cellulose (Avicel), as more complicated structure and multiple components of plant biomass. Lignin acts as a barrier for depolymerization of plant cell wall and its degradation products are known to be toxic to microorganisms [46, 47]. Moreover, xylose occupies a large proportion of the components of plant biomass $[9,48]$. However, the average rate of fixating and channeling $\mathrm{CO}_{2}$ into product malic acid in engineered strains on xylose was approximately 1.7 -fold less than that on glucose (Fig. 4). Therefore, the further engineering of DMCC in M. thermophila is needed to improve overall bioconversion from plant biomass, such

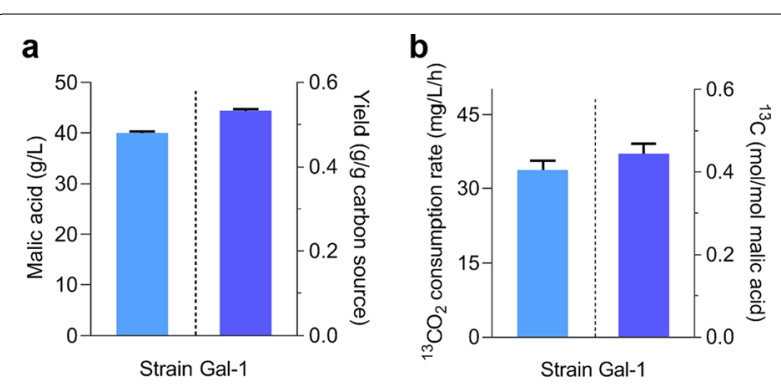

Fig. 6 Production of malic acid by M. thermophila strain Gal-1 grown on raw corncob. a The titer and yield of malic acid was determined after 8 days of fermentation, using raw corncob as the sole carbon source at a final concentration of $75 \mathrm{~g} / \mathrm{L}$. $\mathbf{b}$ The average rate of fixing and channeling ${ }^{13} \mathrm{CO}_{2}$ into malic acid and the ${ }^{13} \mathrm{C}$ content in malic acid. The values and error bars represent means and standard deviations as speeding up pentose utilization and reducing the negative effect of lignin.

\section{Discussion}

Plant biomass and $\mathrm{CO}_{2}$ have many desirable features as industrial raw material to decrease reliance on fossil fuels. Direct conversion of plant lignocellulose and fixing $\mathrm{CO}_{2}$ into the central carbon metabolism of industrial microbes are promising for cost-effective production of value-add compounds in biorefinery. The thermophilic and cellulolytic $M$. thermophila has been engineered to produce malic acid using raw plant biomass as the feedstock without addition of hydrolytic enzyme [10]. In this study, using $M$. thermophila, the DMCC system (direct microbial conversion of biomass with $\mathrm{CO}_{2}$ fixation), a novel strategy for biorefinery from plant cell wall and $\mathrm{CO}_{2}$, was constructed to convert plant biomass and $\mathrm{CO}_{2}$ into malic acid efficiently.

For fixing and channeling $\mathrm{CO}_{2}$ into carbon metabolism for producing value-added compounds, there are two different strategies. One approach is the integration of exogenous biosynthetic production pathways into naturally existing carbon-fixing organisms, such as cyanobacteria and algae. Autotrophic microbes have been engineered to produce chemicals and biofuels from $\mathrm{CO}_{2}$, such as 2,3-butanediol, lactic acid and malic acid [49-51]. However, production performance remains far below industrial feasibility. The other option is to equip heterotrophic fermentation strains with efficient $\mathrm{CO}_{2}$-fixation pathway. Recently, Calvin-Benson-Bassham (CBB) pathway was constructed in heterotrophic microbes to recycle released $\mathrm{CO}_{2}$ into central metabolic pathway for improved carbon efficiency [20,22, 28] and even synthesize sugars and other major biomass components from $\mathrm{CO}_{2}$ [29]. An efficient energy supply is required for biological $\mathrm{CO}_{2}$ fixation. Engineered E. coli and P. pastoris could incorporate $\mathrm{CO}_{2}$ into cell components via heterologous $\mathrm{CBB}$ pathway, requiring reducing power and energy from the supplements, such as pyruvate, formate, and methanol [18, 29, 33]. Using sustainable plant biomass as energy source and actuate $\mathrm{CO}_{2}$-fixation would be a promising strategy for cost-effective bio-manufacturing. In addition, the main components of lignocellulose comprise glucose, xylose, and arabinose. Intermediate ribulose-5-phosphate of pentose catabolism via pentose phosphate pathway can serve as the substrate of PRK. In E. coli and S. cerevisiae, xylose and arabinose were used to drive $\mathrm{CO}_{2}$-fixation of the $\mathrm{CBB}$ cycle $[17,20,32]$. In this work, the $\mathrm{CBB}$ cycle enzymes were successfully introduced into the cellulohydrolytic fungus $M$. thermophila to producing $\mathrm{CO}_{2}$ fixation system, combined with native PYC module to produce malic acid using plant biomass and $\mathrm{CO}_{2}$ as the carbon sources. The proportion 
of carbon atoms from fixed $\mathrm{CO}_{2}$ in the total carbon of malic acid was significantly increased and the average rates of fixing and channeling ${ }^{13} \mathrm{CO}_{2}$ into malic acid achieved $44.4 \mathrm{mg} / \mathrm{L} / \mathrm{h}, 90.7 \mathrm{mg} / \mathrm{L} / \mathrm{h}$ and $80.7 \mathrm{mg} / \mathrm{L} / \mathrm{h}$ in strain CP-51, when grown on xylose, glucose and Avicel, respectively (Fig. 4). With raw corncob as the feedstock, the yield of malic acid produced by the final engineered strain Gal-1 achieved $0.53 \mathrm{~g} / \mathrm{g}$ total plant biomass, representing a $10.4 \%$ increase over the highest reported yield $(0.48 \mathrm{~g} / \mathrm{g})$ [9] and the content of ${ }^{13} \mathrm{C}$ atom in malic acid was up to $0.44 \mathrm{~mol} / \mathrm{mol}$ malic acid. Furthermore, this strategy of synergistic conversion of plant biomass and $\mathrm{CO}_{2}$ can be utilized for the production of other chemicals, such as fumaric and succinic acid.

Rapid utilization of all components of the hydrolysate of plant biomass is the prerequisite for efficient production of biochemical. However, due to the preference of microbes for glucose, pentose utilization is inhibited by glucose presented in the culture, which led to two-stage utilization of sugar mixture and low productivity of target products. It was suggested that D-glucose impairs the simultaneous utilization of pentose mainly by inhibition of pentose uptake [43]. Enhancement of pentose uptake can alleviate this inhibition and facilitate improved pentose utilization and elevated co-fermentation rates of hexose and pentose $[44,52]$. Recently, transporter engineering and directed evolution have been used for rewiring substrate specificity to obtain glucose-insensitive xylose transporters $[45,53]$. Herein, a glucose inhibitionfree xylose transporter was integrated into engineered strain CP-51 for facilitating pentose utilization to actuate $\mathrm{CO}_{2}$-fixation of heterologous CBB pathway and improving co-fermentation rates of hexoses and pentoses for production of malic acid. Titer and yield of malic acid were increased to $76.1 \mathrm{~g} / \mathrm{L}$ and $1.01 \mathrm{~g} / \mathrm{g}$ carbon source, respectively, by conversion of a mixture of sugars derived from plant biomass. In addition, although xylose and arabinose are both pentose, there are dramatic differences in transcriptomic profiles in filamentous fungus when exposed to them in a previous study [9], indicating that that regulation network of xylose catabolism is different from that of arabinose catabolism. Here, it was also observed that titer of malic acid on xylose was obviously below that on arabinose. The exact molecular basis of the two pentose metabolism needs more investigation in the future.

In this study, CBB cycle enzymes, RuBisCO and PRK, were integrated into the metabolic network of the thermophilic fungus $M$. thermophila for enhanced fixation efficiency of $\mathrm{CO}_{2}$. A novel biorefinery system named DMCC was designed and constructed, which can produce $1 \mathrm{t}$ of bulk chemicals (such as malic acid) using less than $2 \mathrm{t}$ of plant biomass, accompanied by the fixation of
$0.14 \mathrm{t} \mathrm{CO}_{2}$. This study provides a novel strategy for producing biochemicals and operating carbon neutral.

\section{Materials and methods}

Strains and culture conditions

Myceliophthora thermophila strain JG207 and its mutants were propagated on $1 \times$ Vogel's minimal medium plates supplemented with $2 \%$ glucose at $35{ }^{\circ} \mathrm{C}$ to obtain conidia after $8 \mathrm{~d}$, and corresponding antibiotic was added when needed for transformant screening.

Escherichia coli DH5 $\alpha$ was employed for vector construction, and was cultivated in Luria-Bertani medium with $100 \mu \mathrm{g} / \mathrm{mL}$ ampicillin or $50 \mu \mathrm{g} / \mathrm{mL}$ kanamycin for plasmid selection.

\section{Plasmid construction}

For the construction of plasmids overexpressing target genes, cbbm (GenBank no. X00286.1) from Rhodospirillum rubrum was codon-optimized on the basis of $\mathrm{Neu}$ rospora crassa codon frequency (http://www.kazusa.or. jp/codon/), artificially synthesized, and inserted between the SpeI and BamHI sites of plasmid pAN52-PtrpC-neoPMtgpdA [9] carrying the neo selectable marker to form overexpression plasmid PgpdA-cbbM-neo, using the NEB Gibson Assembly Kit. Similarly, codon-optimized prk (GenBank no. X07654.1) from Spinacia oleracea, under control of the strong constitutive promoter of $p d c$ (Mycth_112121), was inserted between the BglII and BamHI sites of pAN52-PtrpC-neo-PMtgpdA to generate the vector Ppdc-prk-neo.

The strong constitutive promoter of eif (Mycth_2297659) was employed to efficiently overexpress pentose transporter genes. Site-directed mutation of sugar transporter gene gal-2 from S. cerevisiae was performed using a fusion PCR strategy to generate Gal2M with mutation of residue N376 to phenylalanine (N376F). With the aid of the NEB Gibson Assembly Kit, the amplicons were ligated between the BgIII and BamHI sites of pAN52-PgpdA-bar [10] to generate the corresponding plasmid Peif-gal2M-bar.

Plasmids for sgRNA expression were constructed as described previously [54]. Briefly, specific sgRNA target sites in target genes ( $p c k$, Mycth_2315623; ldh, Mycth_110317; and $p d c$, Mycth_112121) were identified using the sgRNACas9 tool [55] and the $M$. thermophila genome sequence and target gene sequences as the input. Oligos with no off-target probability were selected. The $M$. thermophila U6 promoter and a targetdirected sgRNA fragment were amplified from the U6psgRNA plasmid [54], assembled by overlapping PCR, and cloned into blunt cloning vector pJET1.2 to generate the plasmids U6-pck-sgRNA, U6-ldh-sgRNA, and U6-pdc-sgRNA. 
A vector carrying donor DNA was constructed to perform genomic modification. The $5^{\prime}$ - and $3^{\prime}$-flanking fragments of pck were amplified from the M. thermophila genome. These fragments and selectable marker cassette PtrpC-neo from plasmid p0380-neo [56] were assembled using the NEB Gibson Assembly Kit and cloned into pPK2BarGFPD digested with SpeI and EcoRV to generate the donor DNA sequence donor-pck-neo.

Codon-optimized prk and $c b b M$ were amplified from plasmids Ppdc-prk-neo and PgpdA-cbbM-neo, respectively, using paired primers. prk and $c b b M$ were knockedin to the $l d h$ and $p d c$ loci of the $M$. thermophila genome, respectively, controlled by in situ promoters. $5^{\prime}$ - and $3^{\prime}$-flanking fragments of the $l d h$ and prk codon sequences were assembled to generate donor-ldh-prk. Similarly, $5^{\prime}$ - and $3^{\prime}$-flanking fragments of $p d c$ and $c b b M$ codon sequences were assembled to generate donor-pdc-cbbM.

All vectors were constructed using E. coli $\mathrm{DH} 5 \alpha$ and the target genes cloned into shuttle vectors were sequenced to verify the authenticity of the plasmid construction.

\section{Myceliophthora transformation}

Polyethylene glycol-mediated transformation of $M$. thermophila protoplasts was performed as described previously [57]. For gene overexpression, $10 \mu \mathrm{g}$ linearized plasmid were transformed into $M$. thermophila protoplasts. Putative transformants were selected on agar plates supplemented with corresponding antibiotics and confirmed via PCR amplification of the transgene with paired primers.

For multiple gene replacement involving the $p c k, p d c$, and $l d h$ loci, sgRNA and donor expression cassettes for neo, prk, and $c b b M$ were mixed with Cas9-expression PCR cassette and co-transformed into strain JG207. Putative transformants were selected with $100 \mu \mathrm{g} / \mathrm{mL}$ G418 followed by sequential identification via PCR with paired primers.

\section{Malate-production medium}

Shake-flask cultivation was performed with $50 \mathrm{~mL}$ of medium inoculated with mature spores at a final concentration of $2.5 \times 10^{5}$ spores $/ \mathrm{mL}$ in $250-\mathrm{mL}$ Erlenmeyer flasks to evaluate the malic acid production capabilities of $M$. thermophila. The culture was incubated at $45{ }^{\circ} \mathrm{C}$ with shaking at $150 \mathrm{rpm}$ and samples $(1 \mathrm{~mL})$ were taken at different intervals. Each liter of the cultivation medium contained $75 \mathrm{~g}$ of carbon source, $0.15 \mathrm{~g}$ of $\mathrm{KH}_{2} \mathrm{PO}_{4}, 0.15 \mathrm{~g}$ of $\mathrm{K}_{2} \mathrm{HPO}_{4}, 0.1 \mathrm{~g}$ of $\mathrm{MgSO}_{4} \cdot 7 \mathrm{H}_{2} \mathrm{O}, 0.1 \mathrm{~g}$ of $\mathrm{CaCl}_{2} \cdot 2 \mathrm{H}_{2} \mathrm{O}, 8 \mathrm{~g}$ of Bacto peptone, $1 \mathrm{~mL}$ of biotin $(0.1 \mathrm{~g} / \mathrm{L})$, and $1 \mathrm{~mL}$ of trace element of Vogel's salt, and was sterilized by autoclaving. Subsequently, sterilized $\mathrm{CaCO}_{3}$ was used as a neutralizing agent at a final concentration of $80 \mathrm{~g} / \mathrm{L}$ to keep the
$\mathrm{pH}$ at approximate 6.0. When corncob was used as the feedstock, mechanical pulverization was carried out as follows: corncob was chopped into pieces, pulverized by grinding mill, and then passed through the 80 -mesh size sieve.

\section{Metabolite analysis}

To detect organic acid titer in culture broth, $1 \mathrm{~mL}$ of $2 \mathrm{M}$ sulfuric acid was added into $1-\mathrm{mL}$ well-mixed sample in a $15-\mathrm{mL}$ tube and the mixture was incubated at $80^{\circ} \mathrm{C}$ for $30 \mathrm{~min}$. The mixture was vortexed at intervals to resolve the malate adequately. Subsequently, $2 \mathrm{~mL}$ of distilled water was added, mixed, and an aliquot was used for metabolite analysis.

Malic acid titer was determined by high-performance liquid chromatography (HPLC) using an instrument (e2695; Waters, Manchester, United Kingdom) equipped with an Aminex HPX-87H column (Bio-Rad, Hercules, CA, USA) at $35^{\circ} \mathrm{C}$ and a Waters 2489 UV detector at $40{ }^{\circ} \mathrm{C} ; 5 \mathrm{mM} \mathrm{H}_{2} \mathrm{SO}_{4}$ was used as the mobile phase with a constant flow rate of $0.5 \mathrm{~mL} / \mathrm{min}$. Sugar concentrations were monitored with a Waters 2414 refractive index detector and an Aminex HPX-87P column (Bio-Rad) with distilled water as the mobile phase. Data analysis was performed using a Waters e2695 separation module.

\section{Enzyme assays}

A 50-mL sample was poured into a Büchner funnel equipped with four pieces of gauze, washed with distilled water until most of the $\mathrm{CaCO}_{3}$ was removed, and subsequently collected. Then, mycelia were immediately homogenized in liquid nitrogen and ground into a powder in a prechilled mortar with a prechilled pestle. The paste was transferred into $1 \mathrm{~mL}$ phosphate-buffered saline ( $\mathrm{pH}$ 7.4). After centrifugation for $10 \mathrm{~min}$ at $4{ }^{\circ} \mathrm{C}$, clear supernatant was used for protein qualification and enzyme assay.

Protein concentration in supernatants was measured using a Bio-Rad protein assay kit. RuBisCO activity was measured by the modification of the method described by Xia et al. [17]. The reaction mixture containing $100 \mathrm{mM}$ Tris (pH 7.4), $10 \mathrm{mM} \mathrm{MgCl} 2,20 \mathrm{mM} \mathrm{NaHCO} 3,10 \mathrm{mM}$ $\mathrm{KCl}, 1 \mathrm{mM}$ dithiothreitol, $2 \mathrm{mM}$ oxaloacetate, $5 \mathrm{mM}$ creatine phosphate, $10 \mathrm{U}$ 3-phosphoglycerate kinase, $10 \mathrm{U}$ glyceraldehyde 3-phosphate dehydrogenase, $10 \mathrm{U}$ creatine phosphokinase, $0.2 \mathrm{mM} \mathrm{NADH}$, and crude enzyme solution was incubated for $15 \mathrm{~min}$ at $30{ }^{\circ} \mathrm{C}$. The assay was started by the addition of $0.5 \mathrm{mM}$ ribulose-1,5-bisphosphate and was immediately monitored at $340 \mathrm{~nm}$ for $5 \mathrm{~min}$. RuBisCO activity was defined as the amount of enzyme required to produce $1 \mathrm{nM}$ product per min. 


\section{Sugar uptake assays in $M$. thermophila}

Strains were incubated in $100 \mathrm{~mL}$ of $1 \times$ Vogel's medium containing $2 \%$ glucose at $45^{\circ} \mathrm{C}$ for $18 \mathrm{~h}$, and then washed three times in $1 \times$ Vogel's salts without any carbon source. Subsequently, the mycelia were transferred to Vogel's salts containing $0.5 \%$ sugar (glucose, xylose, or arabinose) for induction for an additional $4 \mathrm{~h}$. After that, the mycelia were washed again as above and resuspended in uptake buffer $[1 \times$ Vogel's salts plus $10 \mathrm{mM}$ sugar (glucose, xylose, or arabinose) and $10 \mu \mathrm{g} / \mathrm{mL}$ cycloheximide] for $20 \mathrm{~min}$. The amount of residual sugar in the supernatant was determined and the fungal biomass was blotted dry and then completely dried at $105^{\circ} \mathrm{C}$ to determine the dry weight for data normalization.

\section{Quantitative real-time PCR analysis}

To assay copy numbers of genes ectopically inserted into the $M$. thermophila genome, fungal genomic DNA was extracted from transformants as described previously [58] and used as the template for real-time qPCR (RT-qPCR). Quantitative PCR was carried out with SYBR Green Realtime PCR Master Mix (Toyobo, Osaka, Japan) and a CFX96 real-time PCR detection system (Bio-Rad), according to the manufacturer's instructions. The reaction mixture (with three replicates) included $1 \mu \mathrm{L}$ of template DNA, $0.4 \mu \mathrm{L}$ of each primer $(10 \mu \mathrm{M}), 10 \mu \mathrm{L}$ of RNA-direct SYBR ${ }^{\circledR}$ Green Realtime PCR Master Mix, and $8.2 \mu \mathrm{L}$ of $\mathrm{H}_{2} \mathrm{O}$. The actin gene (MYCTH_2314852) was used as an internal control. The primers for each gene were optimized to obtain amplification efficiency between 95 and 105\% and only one melting temperature on the melting curve. The primers used for RT-qPCR are listed in Additional file 1: Table S1.

\section{The assay of ${ }^{13} \mathrm{C}$-labeled malic acid}

When ${ }^{13} \mathrm{C}$-tracer analysis was performed to confirm $\mathrm{CO}_{2}$ fixation during production of malic acid, $\mathrm{Ca}^{13} \mathrm{CO}_{3}$ was used as the neutralizer and provider of ${ }^{13} \mathrm{CO}_{2}$. After the fermentation is over, samples were treated with sulfuric acid and diluted with the solution of acetonitrile-methanol-water $(40: 40: 20, \mathrm{v}: \mathrm{v}: \mathrm{v})$ to a suitable concentration and centrifuged for $15 \mathrm{~min}$ at $12,000 \times g$. An ABSciex 5600 TripleTOF liquid chromatography-tandem mass spectrometer (LC-MS/MS) equipped with a UHPLC LC-30A system was employed to determine the relative abundance of malate in supernatants and the chromatography used a zic-HILIC column (Merck, Germany). LCMS/MS analysis was performed as described previously [9]. The ratio of the areas from the resulting multiple reaction monitoring peaks were used to assess the relative abundances of malic acid with ${ }^{13} \mathrm{C}$ atom.

\section{Statistical significance tests}

Unless otherwise noted, statistical significance was tested using a one-tailed homoscedastic (equal variance) $t$-test. All $p$-values were generated using Microsoft Excel 2013 (Microsoft Corporation). n.s. indicates no statistical significance; * represents a $p$-value $<0.05$; $*$ represents a $p$-value $<0.01$; and ${ }^{* * *}$ represents a $p$-value $<0.001$.

\section{Abbreviations}

CBP: Consolidated bioprocessing; CBB cycle: Calvin-Benson-Bassham cycle; PRK: Phosphoribulokinase; RuBisCO: Ribulose-1,5-bisphosphate carboxylaseoxygenase; rTCA pathway: Reductive tricarboxylic acid pathway; CRISPR: Clustered regularly interspaced short palindromic repeats; DMCC: Direct microbial conversion of biomass with $\mathrm{CO}_{2}$ fixation; PYC: Pyruvate carboxylase.

\section{Supplementary Information}

The online version contains supplementary material available at https://doi. org/10.1186/s13068-021-02042-5.

Additional file 1: Table S1. List of PCR primers used in this study.

Additional file 2: Figure S1. PCR analysis of the mutants of $M$. thermophila generated in this study. Figure S2. Copy number assay by RTqPCR. prk and $c b b M$ in the genome of strain CP-1; prk and $c b b M$ in strain CP-51 genomic DNA; gal2M in the genome of strain Gal-1. The values and error bars represent means and standard deviations. Figure S3. Dry cell weight of strain CP-51 grown on xylose for 4 days. The values and error bars represent means and standard deviations of independent triplicate experiments, respectively. The values and error bars represent means and standard deviations. Figure S4. Titers of malic acid produced by strains JG207, CP-1, and CP-51, when grown on glucose and Avicel. Titer of malic acid was determined after 8 days of fermentation. The values and error bars represent means and standard deviations of independent triplicate experiments, respectively. The values and error bars represent means and standard deviations. Figure S5. Sugar utilization of strain Gal-1 when growth in Vogel's minimal medium supplemented with single or multiple sugars derived from lignocellulose. a $40 \mathrm{~g} / \mathrm{L}$ xylose; $\mathbf{b} 40 \mathrm{~g} / \mathrm{L}$ arabinose; c $40 \mathrm{~g} / \mathrm{L}$ glucose; $\mathbf{d} 40 \mathrm{~g} / \mathrm{L}$ glucose and $20 \mathrm{~g} / \mathrm{L}$ xylose; e $40 \mathrm{~g} / \mathrm{L}$ glucose and $20 \mathrm{~g} / \mathrm{L}$ arabinose; $\mathbf{f} 20 \mathrm{~g} / \mathrm{L}$ xylose and $20 \mathrm{~g} / \mathrm{L}$ arabinose; $\mathrm{g} 40 \mathrm{~g} / \mathrm{L}$ glucose, $20 \mathrm{~g} / \mathrm{L}$ xylose, and $20 \mathrm{~g} / \mathrm{L}$ arabinose. The values and error bars represent means and standard deviations.

\section{Acknowledgements}

This work was supported by funding from the Key Project of the Ministry of Science and Technology of China (2018YFA0900500 and 2018YFA0901400), the National Natural Science Foundation of China (32071424, 31972878 and 31761133018), the Chinese Academy of Sciences (XDA21060900), the Tianjin Synthetic Biotechnology Innovation Capacity Improvement Project (TSBICIP-KJGG-015, TSBICIP-CXRC-022 and TSBICIPKJGG-006) and the Youth Innovation Promotion Association of the Chinese Academy of Sciences (2020183 and 2019180). We thank Zhidan Zhang from Tianjin Institute of Industrial Biotechnology for providing support for the analysis of ${ }^{13} \mathrm{C}$-labeled metabolites with LC-MS/MS.

\section{Authors' contributions \\ $J \mathrm{~L}$ and $C T$ conceived the project and wrote the manuscript. $J \mathrm{~L}, \mathrm{BC}, \mathrm{SG}, \mathrm{ZZ}, \mathrm{TS}$ $Y Z, T W$, and WS performed metabolic engineering experiments. JL, $Q L, D L$, and CT analyzed the data. JL and CT wrote the initial paper draft. All authors read and approved the final manuscript.}

Availability of data and materials

All data generated or analyzed during this study are included in this published article and its Additional files. 


\section{Declarations}

Ethics approval and consent to participate

Not applicable.

\section{Consent for publication}

Not applicable.

\section{Competing interests}

The authors declare no competing interests.

\section{Author details}

${ }^{1}$ Key Laboratory of Systems Microbial Biotechnology, Tianjin Institute of Industrial Biotechnology, Chinese Academy of Sciences, Tianjin 300308, China. ${ }^{2}$ National Technology Innovation Center of Synthetic Biology, Tianjin 300308, China. ${ }^{3}$ University of Chinese Academy of Sciences, Beijing 100049, China.

Received: 20 July 2021 Accepted: 11 September 2021

Published online: 23 September 2021

\section{References}

1. Stephanopoulos $G$. Challenges in engineering microbes for biofuels production. Science. 2007;315(5813):801-4.

2. Somerville C, Youngs H, Taylor C, Davis SC, Long SP. Feedstocks for lignocellulosic biofuels. Science. 2010;329(5993):790-2.

3. Lynd LR, van Zyl WH, McBride JE, Laser M. Consolidated bioprocessing of cellulosic biomass: an update. Curr Opin Biotechnol. 2005;16(5):577-83.

4. den Haan R, van Rensburg E, Rose SH, Gorgens JF, van Zyl WH. Progress and challenges in the engineering of non-cellulolytic microorganisms for consolidated bioprocessing. Curr Opin Biotechnol. 2015;33:32-8.

5. Althuri A, Gujjala LKS, Banerjee R. Partially consolidated bioprocessing of mixed lignocellulosic feedstocks for ethanol production. Bioresour Technol. 2017:245:530-9.

6. Olson DG, McBride JE, Shaw AJ, Lynd LR. Recent progress in consolidated bioprocessing. Curr Opin Biotechnol. 2012;23(3):396-405.

7. Gusakov AV. Alternatives to Trichoderma reesei in biofuel production. Trends Biotechnol. 2011;29(9):419-25.

8. Lynd LR, Weimer PJ, van ZyI WH, Pretorius IS. Microbial cellulose utilization: fundamentals and biotechnology. Microbiol Mol Biol Rev. 2002;66(3):506-77.

9. Li J, Lin L, Sun T, Xu J, Ji J, Liu Q, Tian C. Direct production of commodity chemicals from lignocellulose using Myceliophthora thermophila. Metab Eng. 2020;2019(61):416-26.

10. Li J, Gu S, Zhao Z, Chen B, Liu Q, Sun T, Sun W, Tian C. Dissecting cellobiose metabolic pathway and its application in biorefinery through consolidated bioprocessing in Myceliophthora thermophila. Fungal Biol Biotechnol. 2019;6(1):21.

11. Chung D, Cha M, Guss AM, Westpheling J. Direct conversion of plant biomass to ethanol by engineered Caldicellulosiruptor bescii. Proc Natl Acad Sci USA. 2014;111(24):8931-6.

12. Mintya JJ, Singera ME, Scholzb SA, Baea CH, Ahna JH, Fosterc CE, Liaod JC, Lina XN. Design and characterization of synthetic fungal-bacterial consortia for direct production of isobutanol from cellulosic biomass. Proc Natl Acad Sci USA. 2013;110:14592-7.

13. Zhao $\mathrm{C}$, Chen $\mathrm{S}$, Fang $\mathrm{H}$. Consolidated bioprocessing of lignocellulosic biomass to itaconic acid by metabolically engineering Neurospora crassa. Appl Microbiol Biotechnol. 2018;102(22):9577-84.

14. Steiger MG, Mattanovich D, Sauer M. Microbial organic acid production as carbon dioxide sink. FEMS Microbiol Lett. 2017. https://doi.org/10. 1093/femsle/fnx212.

15. Mattozzi MD, Ziesack M, Voges MJ, Silver PA, Way JC. Expression of the sub-pathways of the Chloroflexus aurantiacus 3-hydroxypropionate carbon fixation bicycle in E. coli: toward horizontal transfer of autotrophic growth. Metab Eng. 2013;16:130-9.

16. Bogorad IW, Chen CT, Theisen MK, Wu TY, Schlenz AR, Lam AT, Liao JC. Building carbon-carbon bonds using a biocatalytic methanol condensation cycle. Proc Natl Acad Sci USA. 2014;111(45):15928-33.
17. Xia PF, Zhang GC, Walker B, Seo SO, Kwak S, Liu JJ, Kim H, Ort DR, Wang SG, Jin YS. Recycling carbon dioxide during xylose fermentation by engineered Saccharomyces cerevisiae. ACS Synth Biol. 2017;6(2):276-83.

18. Gassler T, Sauer M, Gasser B, Egermeier M, Troyer C, Causon T, Hann S, Mattanovich D, Steiger MG. The industrial yeast Pichia pastoris is converted from a heterotroph into an autotroph capable of growth on $\mathrm{CO}_{2}$. Nat Biotechnol. 2020;38(2):210-6.

19. von Borzyskowski LS, Carrillo M, Leupold S, Glatter T, Kiefer P, Weishaupt R, Heinemann M, Erb TJ. An engineered Calvin-Benson-Bassham cycle for carbon dioxide fixation in Methylobacterium extorquens AM1. Metab Eng. 2018:47:423-33.

20. Zhuang ZY, Li SY. Rubisco-based engineered Escherichia coli for in situ carbon dioxide recycling. Bioresour Technol. 2013;150:79-88.

21. Guadalupe-Medina V, Wisselink HW, Luttik MAH, de Hulster E, Daran JM, Pronk JT, van Maris AJA. Carbon dioxide fixation by Calvin-cycle enzymes improves ethanol yield in yeast. Biotechnol Biofuels. 2013;6(1):125.

22. Tseng IT, Chen YL, Chen CH, Shen ZX, Yang CH, Li SY. Exceeding the theoretical fermentation yield in mixotrophic Rubisco-based engineered Escherichia coli. Metab Eng. 2018;47:445-52.

23. Claassens NJ, Sousa DZ, Dos Santos VA, de Vos WM, van der Oost J. Harnessing the power of microbial autotrophy. Nat Rev Microbiol. 2016;14(11):692-706

24. Bassham JA, Benson AA, Kay LD, Harris AZ, Wilson AT, Calvin M. The path of carbon in photosynthesis. 21. The cyclic regeneration of carbon dioxide acceptor. J Am Chem Soc. 1954;76(7):1760-70.

25. Sanchez-Andrea I, Guedes IA, Hornung B, Boeren S, Lawson CE, Sousa DZ, Bar-Even A, Claassens NJ, Stams AJM. The reductive glycine pathway allows autotrophic growth of Desulfovibrio desulfuricans. Nat Commun. 2020;11(1):5090.

26. Martin W, Schnarrenberger C. The evolution of the Calvin cycle from prokaryotic to eukaryotic chromosomes: a case study of functional redundancy in ancient pathways through endosymbiosis. Curr Genet. 1997;32(1):1-18.

27. Erb TJ, Zarzycki J. A short history of RubisCO: the rise and fall of Nature's predominant $\mathrm{CO}_{2}$ fixing enzyme. Curr Opin Biotechnol. 2018;49:100-7.

28. Yang CH, Liu EJ, Chen YL, Ou-Yang FY, Li SY. The comprehensive profile of fermentation products during in situ $\mathrm{CO}_{2}$ recycling by Rubisco-based engineered Escherichia coli. Microb Cell Fact. 2016;15(1):133.

29. Antonovsky N, Gleizer S, Noor E, Zohar Y, Herz E, Barenholz U, Zelcbuch L, Amram S, Wides A, Tepper $\mathrm{N}$, et al. Sugar synthesis from $\mathrm{CO}_{2}$ in Escherichia coli. Cell. 2016;166(1):115-25.

30. Mueller-Cajar O, Morell M, Whitney SM. Directed evolution of rubisco in Escherichia coli reveals a specificity-determining hydrogen bond in the form II enzyme. Biochemistry. 2007;46(49):14067-74.

31. Parikh MR, Greene DN, Woods KK, Matsumura I. Directed evolution of RuBisCO hypermorphs through genetic selection in engineered $E$. coli. Protein Eng Des Sel. 2006;19(3):113-9.

32. Li YJ, Wang MM, Chen YW, Wang M, Fan LH, Tan TW. Engineered yeast with a $\mathrm{CO}_{2}$-fixation pathway to improve the bio-ethanol production from xylose-mixed sugars. Sci Rep. 2017;7:43875.

33. Gleizer S, Ben-Nissan R, Bar-On YM, Antonovsky N, Noor E, Zohar Y, Jona G, Krieger E, Shamshoum M, Bar-Even A, Milo R. Conversion of Escherichia coli to generate all biomass carbon from $\mathrm{CO}_{2}$. Cell. 2019:179(6):1255-63.

34. Zelle RM, de Hulster E, van Winden WA, de Waard P, Dijkema C, Winkler AA, Geertman JM, van Dijken JP, Pronk JT, van Maris AJ. Malic acid production by Saccharomyces cerevisiae: engineering of pyruvate carboxylation, oxaloacetate reduction, and malate export. Appl Environ Microbiol. 2008;74(9):2766-77.

35. Xu Q, Li S, Fu Y, Tai C, Huang H. Two-stage utilization of corn straw by Rhizopus oryzae for fumaric acid production. Bioresour Technol. 2010;101(15):6262-4.

36. Peleg Y, Stieglitz B, Goldberg I. Malic acid accumulation by Aspergillus flavus. I. biochemical aspects of acid biosynthesis. Appl Microbiol Biotechnol. 1988;28(1):69-75.

37. Knuf C, Nookaew I, Remmers I, Khoomrung S, Brown S, Berry A, Nielsen J. Physiological characterization of the high malic acid-producing Aspergillus oryzae strain 2103a-68. Appl Microbiol Biotechnol. 2014;98(8):3517-27.

38. Dai ZX, Zhou HY, Zhang SJ, Gu HL, Yang Q, Zhang WM, Dong WL, Ma JF, Fang $Y$, Jiang M, Xin FX. Current advance in biological production of malic 
acid using wild type and metabolic engineered strains. Bioresour Technol. 2018;258:345-53.

39. Singh B. Myceliophthora thermophila syn. Sporotrichum thermophile: a thermophilic mould of biotechnological potential. Crit Rev Biotechnol. 2016;36(1):59-69.

40. Berka RM, Grigoriev IV, Otillar R, Salamov A, Grimwood J, Reid I, Ishmael N, John T, Darmond C, Moisan MC, et al. Comparative genomic analysis of the thermophilic biomass-degrading fungi Myceliophthora thermophila and Thielavia terrestris. Nat Biotechnol. 2011;29(10):922-7.

41. Zhang $X$, Wang $X$, Shanmugam KT, Ingram LO. L-Malate production by metabolically engineered Escherichia coli. Appl Environ Microbiol. 2011;77(2):427-34.

42. Dos Santos Gomes AC, Falkoski D, Battaglia E, Peng M, Nicolaude Almeida M, Coconi Linares N, Meijnen JP, Visser J, de Vries RP. Myceliophthora thermophila Xyr 1 is predominantly involved in xylan degradation and xylose catabolism. Biotechnol Biofuels. 2019;12:220

43. Subtil T, Boles E. Competition between pentoses and glucose during uptake and catabolism in recombinant Saccharomyces cerevisiae. Biotechnol Biofuels. 2012;5:14.

44. Li J, Xu J, Cai P, Wang B, Ma Y, Benz JP, Tian C. The functional analysis of two $L$-arabinose transporters from filamentous fungi reveals promising characteristics for improved pentose utilization in yeast. Appl Environ Microbiol. 2015;81(12):4062-70.

45. Farwick A, Bruder S, Schadeweg V, Oreb M, Boles E. Engineering of yeast hexose transporters to transport D-xylose without inhibition by D-glucose. Proc Natl Acad Sci USA. 2014;111(14):5159-64.

46. Boonsombuti A, Luengnaruemitchai A, Wongkasemjit S. Enhancement of enzymatic hydrolysis of corncob by microwave-assisted alkali pretreatment and its effect in morphology. Cellulose. 2013;20(4):1957-66.

47. Schuster BG, Chinn MS. Consolidated bioprocessing of lignocellulosic feedstocks for ethanol fuel production. Bioenergy Res. 2013;6(2):416-35.

48. Wang B, Cai P, Sun W, Li J, Tian C, Ma Y. A transcriptomic analysis of Neurospora crassa using five major crop residues and the novel role of the sporulation regulator rca-1 in lignocellulase production. Biotechnol Biofuels. 2015;8:21.

49. Angermayr SA, van der Woude AD, Correddu D, Vreugdenhil A, Verrone V, Hellingwerf KJ. Exploring metabolic engineering design principles for the photosynthetic production of lactic acid by Synechocystis sp. PCC6803. Biotechnol Biofuels. 2014;7:99.

50. Hu G, Zhou J, Chen X, Qian Y, Gao C, Guo L, Xu P, Chen W, Chen J, Li Y, Liu L. Engineering synergetic $\mathrm{CO}_{2}$-fixing pathways for malate production. Metab Eng. 2018:47:496-504.

51. Kanno M, Carroll AL, Atsumi S. Global metabolic rewiring for improved $\mathrm{CO}_{2}$ fixation and chemical production in cyanobacteria. Nat Commun. 2017:8:14724

52. Subtil T, Boles E. Improving L-arabinose utilization of pentose fermenting Saccharomyces cerevisiae cells by heterologous expression of L-arabinose transporting sugar transporters. Biotechnol Biofuels. 2011;4:38.

53. Young EM, Tong A, Bui H, Spofford C, Alper HS. Rewiring yeast sugar transporter preference through modifying a conserved protein motif. Proc Natl Acad Sci USA. 2014;111(1):131-6.

54. Liu Q, Gao R, Li J, Lin L, Zhao J, Sun W, Tian C. Development of a genomeediting CRISPR/Cas9 system in thermophilic fungal Myceliophthora species and its application to hyper-cellulase production strain engineering. Biotechnol Biofuels. 2017;10:1.

55. Xie S, Shen B, Zhang C, Huang X, Zhang Y. sgRNAcas9: a software package for designing CRISPR sgRNA and evaluating potential off-target cleavage sites. PLOS ONE. 2014;9(6):e100448.

56. Xu J, Li J, Lin L, Liu Q, Sun W, Huang B, Tian C. Development of genetic tools for Myceliophthora thermophila. BMC Biotechnol. 2015;15(35):1-10.

57. Yang $F$, Gong Y, Liu G, Zhao S, Wang J. Enhancing cellulase production in thermophilic fungus Myceliophthora thermophila ATCC42464 by RNA interference of cre1 gene expression. J Microbiol Biotechnol. 2015;25(7):1101-7.

58. Tian C, Beeson WT, lavarone AT, Sun J, Marletta MA, Cate JH, Glass NL. Systems analysis of plant cell wall degradation by the model filamentous fungus Neurospora crassa. Proc Natl Acad Sci USA. 2009;106(52):22157-62.

\section{Publisher's Note}

Springer Nature remains neutral with regard to jurisdictional claims in published maps and institutional affiliations.
Ready to submit your research? Choose BMC and benefit from:

- fast, convenient online submission

- thorough peer review by experienced researchers in your field

- rapid publication on acceptance

- support for research data, including large and complex data types

- gold Open Access which fosters wider collaboration and increased citations

- maximum visibility for your research: over $100 \mathrm{M}$ website views per year

At BMC, research is always in progress.

Learn more biomedcentral.com/submissions 